\title{
Keeping pace with marine heatwaves
}

2

3

Neil J. Holbrook ${ }^{1,2+}$, Alex Sen Gupta ${ }^{3,4}$, Eric C. J. Oliver ${ }^{5}$, Alistair J. Hobday ${ }^{6}$, Jessica A. Benthuysen ${ }^{7}$, Hillary A. Scannell ${ }^{8}$, Dan A. Smale ${ }^{9}$ and Thomas Wernberg ${ }^{10,11}$

1. Institute for Marine and Antarctic Studies, University of Tasmania, Hobart, Australia

2. Australian Research Council Centre of Excellence for Climate Extremes, University of Tasmania, Hobart, Australia

3. Climate Change Research Centre, The University of New South Wales, Sydney, Australia

4. Australian Research Council Centre of Excellence for Climate Extremes, The University of New South Wales, Sydney, Australia

5. Department of Oceanography, Dalhousie University, Halifax, Canada

6. CSIRO Oceans and Atmosphere, Hobart, Australia

7. Australian Institute of Marine Science, Crawley, Australia

8. School of Oceanography, University of Washington, Seattle, WA, USA

9. Marine Biological Association of the United Kingdom, The Laboratory, Citadel Hill, Plymouth, UK

10. UWA Oceans Institute and School of Biological Sciences, The University of Western Australia, Crawley, Australia

11. Department of Science and Environment, Roskilde University, Roskilde, Denmark

†Email : neil.holbrook@utas.edu.au 


\section{Abstract}

Marine heatwaves (MHWs) are prolonged extreme oceanic warm water events. They can have devastating impacts on marine ecosystems - for example, causing mass coral bleaching and substantial declines in kelp forests and seagrass meadows - with implications for the provision of ecological goods and services. Effective adaptation and mitigation efforts by marine managers can benefit from improved MHW predictions, which at present are inadequate. In this Perspective, we explore MHW predictability on shortterm, interannual to decadal, and centennial timescales, focusing on the physical processes that offer prediction. While there may be potential predictability of MHWs days to years in advance, accuracy will vary dramatically depending on the regions and drivers. Skilful MHW prediction has the potential to provide critical information and guidance for marine conservation, fisheries and aquaculture management. However, to develop effective prediction systems, better understanding is needed of the physical drivers, subsurface MHWs, and predictability limits.

\section{[H1] Introduction}

Prolonged extreme ocean warming events - also known as marine heatwaves (MHWs) - can severely impact marine ecosystems and the services they provide ${ }^{1-6}$. Yet despite their significance, dedicated and coordinated research only became prominent following the extreme event off Western Australia in $2011^{7,8}$. Indeed, it was during this event that the term 'marine heatwave' was first used to characterise an extensive, persistent and extreme ocean temperature event ${ }^{9}$ (Box 1), spurring a new wave of research into their physical processes and corresponding impacts.

Since 2011, MHWs have been observed and analysed both retrospectively and contemporaneously, and are now recognised to occur over various spatio-temporal scales. For example, given the ocean's heat capacity and dynamical scales, MHW events can persist for weeks to years ${ }^{10-16}$. They further vary in spatial extent and depth depending on the processes that cause and maintain them, as well as the geometry of the regions in which they occur. For instance, MHWs can be locally confined to individual bays ${ }^{17}$, around small islands or along short sections of coastline, or be broadly distributed over regional seas ${ }^{10,18}$, ocean basins ${ }^{15,19}$, or even spanning multiple oceans ${ }^{20,21}$ (for a map of major MHW events, see Fig. 1).

As well as the physical drivers, the ecological impacts of MHWs have also been studied in considerable depth. The effects include biodiversity loss and changes in species behaviour or performance ${ }^{3,7}$, loss of genetic diversity and adaptive capacity ${ }^{22}$, economic impacts from changes in fishery catch rates ${ }^{1,23-25}$, and mortality or altered performance of farmed aquaculture species ${ }^{13}$.The impacts of MHWs are particularly evident on coral reefs (promoting widespread bleaching, including pan-tropical events ${ }^{26}$ ), kelp forests (driving significant loss of kelp forest habitats off the coast of Western Australia, New Zealand, Mexico and the North Atlantic ${ }^{7,27-30}$ ), and seagrass meadows (wherein substantial declines have been observed ${ }^{31}$ ). At higher trophic levels, MHWs have also impacted economically important species including lobster and snow crab in the northwest Atlantic ${ }^{1,32}$, lobster, crabs, abalone and scallops off Western Australia ${ }^{24,33}$, and numerous species in the 
northeast Pacific ${ }^{34}$. In some cases, MHWs have even been linked with increased whale entanglements ${ }^{35}$.

Given the evidence for potentially devastating impacts resulting from MHWs, there is a critical need for skilful prediction to inform effective response and adaptation strategies. This urgency is amplified by anthropogenic warming which has increased MHW occurrences by $50 \%$ over the past several decades ${ }^{36}$, a change which is also projected to increase in the future ${ }^{37,38}$ (Fig. 2). Despite improved process-based understanding ${ }^{14}$, knowledge of MHW predictability and present MHW prediction systems are in their infancy. Hence, there is a compelling need to understand and improve MHW predictability in order to guide marine conservation, fisheries management and aquaculture practises in a warming world. In this Perspective, we explore the mechanisms and potential for MHW predictability across a range of time scales. We first consider the physical mechanisms that cause MHWs, before then exploring the importance of MHW event monitoring as an activity to improve our understanding of MHW precursors, processes, and forecasts. Using this knowledge, we subsequently outline the potential for MHW predictability. Finally, we address future challenges and opportunities for $\mathrm{MHW}$ research, including those arising from climate change.

\section{[H1] Physical mechanisms}

A range of physical mechanisms can lead to the warming of ocean waters (Fig. 3). These include enhanced solar radiation into the ocean, supressed latent and sensible heat losses from the ocean to the atmosphere, shoaling of the mixed layer due to increased stratification, increased horizontal transport (advection) of heat, and reduced vertical heat transport associated with supressed mixing, reduced coastal upwelling or Ekman pumping processes that bring cool deep water to the surface (see ref ${ }^{14}$ for more in-depth discussion). Furthermore, elevated upper ocean heat content or the re-emergence of warm anomalies from the subsurface can precondition increased likelihood of MHW occurrence. The amplification or suppression of these processes, either in isolation or collectively, can promote or inhibit MHW development driven by local air-sea interactions and feedbacks, and large-scale modes of climate variability acting locally or remotely. Here, we detail these physical processes and discuss their potential for predicting MHW occurrences on a range of timescales.

\section{[H2] Coupled air-sea interactions and atmospheric preconditioning.}

Many of the iconic extratropical MHWs (e.g. The Blob, central South Pacific) have been associated with persistent high-pressure systems (or blocking highs) over the ocean and their resulting air-sea interactions. Atmospheric blocking reduces cloud cover, enhances insolation and suppresses surface wind speeds, resulting in hot, dry weather. Collectively these conditions reduce sensible and latent ocean heat loss, but increase solar radiative heating, in turn warming sea surface temperatures (SSTs) ${ }^{14,19,39,40}$. Given that blocking highs have large spatial scales and can persist for weeks to months, they have the potential to substantially raise ocean temperatures over a large geographic region for a considerable duration, as reflected in the characteristics of MHWs they promote. For example, key events 
occurred during 2003 in the Mediterranean Sea ${ }^{10,41}, 2009 / 10$ in the central South Pacific ${ }^{19}$, 2012 in the northwest Atlantic ${ }^{12,42}, 2013 / 14$ in the northeast Pacific ${ }^{39}$, and 2017/18 in the Tasman Sea ${ }^{43,44}$ (Fig. 1).

While these events are related to atmospheric blocking, the specific mechanisms vary. The 2009/10 MHW in the central South Pacific was generated by Rossby wave-related atmospheric anomalies arising from the Central Pacific El Niño ${ }^{19}$. By contrast, the 2003 Mediterranean Sea ${ }^{10,45}$ and 2017/18 Tasman Sea MHWs ${ }^{43,44}$ formed through enhanced radiative heat fluxes caused by concurrent atmospheric heatwaves. In the case of the 2012 northwest Atlantic ${ }^{12,42}$ and 2013/2014 northeast Pacific MHWs ${ }^{15,39}$, atmospheric preconditioning was important. Specifically, persistent atmospheric weather patterns through the winter reduced wintertime heat loss from the ocean to the atmosphere, keeping the upper ocean warmer and preconditioning it to increased MHW likelihood in the following seasons. The 2013 North Pacific blocking pattern was so extreme and persistent that it was given the nickname the "ridiculously resilient ridge" ${ }^{46}$, referring to a large and unusual region of high sea level pressure that was unprecedented since at least the $1980 \mathrm{~s}^{39}$.

\section{[H2] Oceanic preconditioning}

Oceanic preconditioning of warm temperature anomalies can result from the process of reemergence ${ }^{47}$ : if heat anomalies form during winter when the mixed layer is deep, subsurface anomalies can become uncoupled from the surface ocean in summer when the mixed layer shoals. When the mixed layer deepens again during the subsequent winter, the persistent subsurface anomalies are re-entrained into the mixed layer, making the surface ocean warmer ${ }^{47}$. Mixed layer depths are also important for modulating the response of the surface ocean to heat fluxes. For example, when mixed layers are shallower than normal, they will warm faster for a given input of heat ${ }^{48}$. Indeed, an anomalously shallow mixed layer when net heat fluxes are into the ocean could increase the likelihood of summer MHWs, even in the absence of anomalously large surface heat fluxes ${ }^{49}$. However, we also note the identification of a separate measure of oceanic preconditioning based on ocean heat content over greater depths and longer time scales, due to ocean circulation changes. Specifically, an analysis of Argo data and model results in the Tasman Sea indicates that interannual to decadal time scale variations in ocean heat content to $2000 \mathrm{~m}$ depth, as a measure of the background state, can precondition the development of MHWs, requiring less surface heating to develop a MHW when superimposed on an already warm ocean ${ }^{50}$.

\section{[H2] Modulation by climate modes and teleconnections}

Modes of climate variability - which operate on time scales from intra-seasonal (MaddenJulian Oscillation (MJO)), through interannual (EI Niño - Southern Oscillation (ENSO), Indian Ocean Dipole (IOD)), to decadal) - are known to modulate the frequency, intensity and duration of $\mathrm{MHWs}{ }^{14,36,51}$. These modes can modulate ocean temperatures, including the development of regional MHWs, directly or remotely via atmospheric or oceanic teleconnections which reverberate the effects globally ${ }^{14,52}$. 
On intra-seasonal timescales, the MJO influences atmospheric circulation by suppressing convection and increasing Ekman pumping off northwest Australia, specifically during MJO phases $2-5^{53}$. This process preferentially supports warmer SSTs and increases the likelihood of MHWs off Western Australia ${ }^{54}$. Conversely, the MJO has also been associated with enhanced convection, capable of exciting a Rossby wave train through to the extratropics that effectively sets up a blocking high, which forces MHWs in the southwest Atlantic Ocean 40 .

On interannual timescales, ENSO events play a substantial role in influencing MHW likelihood, not only in the tropical Pacific but also in regions remote to ENSO's centre-ofaction. El Niño events are associated with increased SSTs in the central and eastern tropical Pacific, resulting in MHWs through the dynamic response of the thermocline to wind stress changes at the surface, Kelvin wave propagation across the Pacific, and reduced upwelling ${ }^{14}$. El Niño events have also been associated with reduced strength of the subtropical northeasterly trade winds which, in turn, reduce evaporation, increase local SSTs, and trigger a positive thermodynamic wind-evaporation-SST feedback ${ }^{15}$. This feedback subsequently activates meridional modes, which propagate and amplify SST from the subtropics into the central equatorial Pacific. There, the positive SST anomalies favour the development of EI Niño and tropical convection, exciting atmospheric Rossby waves which teleconnect to the extratropics, that aid persistence ${ }^{15}$. Conversely, La Niña events can remotely elevate SSTs off Western Australia via the propagation of oceanic Kelvin waves and by strengthening heat transport through the Leeuwin Current, increasing the likelihood of MHWs ${ }^{48,55}$. Thus, the phase of ENSO (along with other modes) is important in enhancing or suppressing MHWs in different regions across the globe ${ }^{14,36}$.

On longer time scales, oceanic Rossby waves can propagate westward for years to decades across ocean basins and modulate ocean heat content and the local vertical structure along their path. In particular, it has been shown that oceanic Rossby waves generated by wind changes in the interior South Pacific can modulate poleward transport through the Tasman Sea ${ }^{56}$ and enhance MHW event likelihoods there ${ }^{57}$. This likelihood is increased despite the fact that the East Australian Current Extension region is eddy-rich, with high-frequency variability occurring on timescales of weeks to months. This oceanic teleconnection process provides an additional ocean heat content modulation mechanism to effectively load the dice' for increased MHW potential predictability in the Tasman Sea.

\section{[H1] Monitoring marine heatwaves}

Coupled with understanding of the physical processes contributing to MHW development, ocean temperature monitoring programs are crucial for their identification and categorisation. The near real-time monitoring of $\mathrm{MHWs}$ requires resources to deliver temperature data on a range of spatial scales and depths. In this regard, satellite sensors provide a suite of global and regional ocean surface information, including SST, sea level, currents, and winds. Near real-time in-situ data from Argo floats, gliders, and moorings provide information on subsurface conditions, such as mixed layer depth and heat content. 
Integrated ocean data systems that incorporate these multiple data streams can offer region-specific information for monitoring MHWs. For example, Australia's Integrated Marine Observing System (IMOS) provides near real-time summaries of surface currents and SST which, when referenced against climatology data, indicates the presence of MHWs around Australia - representing valuable information for the public, aquaculture industries, tourism operators in the marine environment, and local communities.

\section{[H2] Event-based monitoring}

Event-based monitoring can offer targeted information for marine stakeholders once a MHW event has commenced. For example, identifying properties of a MHW, such as its vertical extent, may provide information on its persistence or potential disruption to marine ecosystems (Table 1); a shallow MHW may be more likely to weaken if strengthening winds lead to deep mixing, whereas a deep MHW offshore would persist even if winds intensified.

230

During a MHW, rapid deployment of specific equipment can augment standard and integrated systems and may target regions where infrastructure is not present or does not meet the needs for near real-time monitoring. For instance, existing technology such as autonomous underwater vehicles, vertical profiling instruments and undulating towed vehicles can be manoeuvred to resolve a MHW's vertical structure and investigate contributing physical processes. An IMOS program to examine the emergence, maintenance and decay phases of the 2018/19 Tasman Sea MHW, for example, revealed the potential for such monitoring approaches. During this program, Slocum gliders deployed off Tasmania provided high temporal and spatial sampling over the continental shelf, informing the depth and characteristics of the anomalously warm water event (Fig. 4). Near real-time data were shared with regional stakeholders, including local marine industries such as salmon and oyster aquaculture, stimulating interest and intensifying demand for predictive capability. Indeed, such real-time information, achieved through event-based monitoring, can inform adaptation responses for multiple stakeholders, demonstrating the importance of translating raw data streams into visual results.

\section{[H2] Monitoring subsurface MHWs}

While remote sensing, in combination with surface drifting buoys and ship underway data, provides high resolution SST data for both historical and real-time analyses of MHW surface characteristics, it is not only surface properties that need attention. MHWs can also exhibit considerable depth penetration, or exist at depth with no surface expression, necessitating subsurface data ${ }^{58,59}$. Yet, the ability to characterise subsurface MHWs in both the open ocean ${ }^{59}$ and coastal regions ${ }^{58}$ is challenged by the sparsity of observations and the absence of continuous, long-term time-series in the historical record (such as data from eXpendable BathyThermograph (XBT), conductivity, temperature and depth (CTD), gliders, and Argo profiles).

These challenges hinder the development of robust and spatially complete subsurface temperature climatologies needed for statistical assessments of MHWs. Indeed, while some datasets exist ${ }^{60,61}$, they do not extend to coastal regions owing to an absence of Argo profiles $^{62}$. Nevertheless, analyses of $\mathrm{MHW}$ vertical structure and corresponding processes 
have been attempted through the use of long-term mooring sites ${ }^{20,58}$, autonomous floats in regional seas (such as the western Tasman Sea ${ }^{59}$ ), and dynamical ocean models or reanalyses that assimilate ocean observations ${ }^{63,64}$. Each of these approaches have known limitations; mooring sites provide information for single points in space, and reanalysis data are based on model-synthesised sparse observations, meaning the products are only as good as the quality and quantity of observations they assimilate, and their distribution. Consideration of how to identify MHWs using sub-optimal data is, therefore, important for future work ${ }^{65}$. Better understanding of the relevant time scales of subsurface MHWs, which can be longer than those at the surface ${ }^{59}$, may alleviate some of the demands on high temporal frequency sampling. It is clear, however, that without improved subsurface characterisation of MHWs - with bearing on surface recharge, heat storage and mixing their prediction potential remains limited.

\section{[H1] Predicting MHWs}

As discussed previously, MHW occurrences can depend on modes of climate variability $14,36,51$, the background ocean state (heat content, mixed layer depth) ${ }^{49,50}$, ocean circulation 13 , remote teleconnections $14,15,40,57$, and the presence of weather systems such as atmospheric blocking ${ }^{39,40,43}$. In many instances, these drivers are themselves at least partially predictable, especially in regard to climate modes ${ }^{66}$, suggesting that MHW events are potentially predictable many months ahead ${ }^{14,18,57}$. Here we outline the need for understanding MHW predictability, their timescales, and the development of forecast systems.

\section{[H2] The benefit and need for MHW prediction}

Skilful prediction of MHW events, and their intensity, duration, depth and spatial extent, is expected to be of great value to marine resource users, and managers of fisheries, aquaculture and conservation ${ }^{66-68}$. For instance, short-term forecasts of a few days to weeks ${ }^{69}$ would allow for active management strategies to be implemented, such as harvesting or relocating farmed species in aquaculture industries that would likely suffer mortality under MHW conditions. With predictive capabilities, it may also be possible to ameliorate stressful conditions through short-term active interventions such as cooling or shading, as is currently implemented in Australian fishery and aquaculture sectors in response to seasonal forecasts of adverse conditions (e.g., water temperature, rainfall, and air temperature) ${ }^{70}$. Indeed, on seasonal timescales, forecasts can be used to inform strategic fisheries management decisions (target species, quotas, timings) or to implement temporary protected areas. While most applications of MHW predictions seek to support mitigation of detrimental ecological consequences, short- to medium-term prediction of MHWs could also bring opportunities. For example, the $2011 \mathrm{MHW}$ in Western Australia led to the temporary appearance of marine megafauna (whale sharks, manta rays, tiger sharks, turtles) and recreationally important fish species well outside their normal range ${ }^{9}$, 
Anticipating regions that may be affected by decadal and longer-term MHW intensification would also guide placement of permanent fully protected areas (such as within climatic refugia ${ }^{71}$ ), as well as inform fisheries management approaches by future-proofing target species for fisheries and aquaculture ${ }^{24}$. Moreover, longer term prediction can help focus conservation efforts such as assisted evolution or early restoration in sensitive habitats and regions ${ }^{31}$. Skilful prediction can identify areas where mitigation strategies might have limited utility as it may not be economically feasible or technically possible to mitigate all the impacts on marine ecosystems ${ }^{72}$.

\section{[H2] Predictability timescales}

The degree to which MHWs are predictable requires knowledge of how the relevant physical drivers and processes interact in time, from days (SST persistence), to weeks (blocking systems and atmospheric teleconnections), to months (oceanic preconditioning), and years (low frequency climate modes and oceanic teleconnections). Given the heat capacity, persistence and propagation timescales of oceanic processes (such as from oceanic Rossby waves) are much larger than those for the atmosphere (for instance, from persistent blocking), MHW development is expected to have longer predictability lead times in regions where oceanic processes dominate (Table 1, Fig. 5).

For example, MHW forecasts with lead times of 7-10 days may be possible when air-sea interactions (such as from a blocking event) dominate MHW development. However, at week-to-month leads, preconditioning factors from mixed later depth (MLD) or ocean heat content enhance predictability potential ${ }^{49,50}$. For example, if the MLD in boundary current and extension regions is relatively shallow leading into summer, anomalously warm SSTs may be expected in the summer season also ${ }^{49}$. Information on ocean advection processes and internal variability (from large-scale eddies, for example), might also improve MHW forecast potential on similar timescales, as has been found for seasonal forecasts ${ }^{73}$ (Table 1). Atmospheric and oceanic circulations are recognised in describing $\mathrm{MHW}$ types along the eastern Tasmanian shelf region, where persistence and intensity are related to the relative contribution of the East Australian Current and atmospheric heat input ${ }^{63}$.

Climate modes and their teleconnections are also expected to influence MHW predictability on subseasonal to seasonal ${ }^{18,40,54,74}$ and interannual to decadal timescales ${ }^{14,57}$. Most climate modes have some degree of predictability, or at least persistence, and can therefore provide potential sources of MHW predictability; for example, ENSO can be predicted $\sim 6$ months in advance, while individual phases of the Pacific Decadal Oscillation (or Interdecadal Pacific Oscillation) persist for decades ${ }^{66}$. For example, MHWs off Western Australia are linked to ENSO and the Madden-Julian Oscillation indicating some degree of MHW predictability on subseasonal to seasonal timescales in that region. Moreover, atmospheric blocking events at midlatitudes via remote teleconnections also offer some predictability, albeit at much shorter timescales ${ }^{40}$. While blocking can be influential to $\mathrm{MHW}$ development, the realistic simulation of blocking is a challenge, as is the forecasting of these 
blocking events ${ }^{75-78}$. While atmospheric blocking may increase the likelihood of MHW event occurrence, other short-term oceanic processes can work against the blocking such that the event does not occur. This creates significant uncertainty around MHW event likelihood based on simulations of blocking and blocking forecasts.

Other processes can also offer predictive power. The clustering of ocean eddies in western boundary currents ${ }^{79}$, for example, contribute potentially predictable changes in ocean temperature extremes ${ }^{63,80,81}$. Remotely forced oceanic Rossby wave teleconnections which take months to many years to propagate westward across ocean basins - also hold considerable promise for multi-year prediction of MHW likelihood in the Tasman Sea region 57 .

\section{[H2] Developing forecast systems}

Marine managers can gain valuable information from seasonal MHW forecasts. However, skilful forecasts are not easily achieved. For example, a recent assessment of seasonal forecast skill from the US National Center for Environmental Prediction's Climate Forecast System in 'The Blob' region had little success ${ }^{82}$. Meanwhile, a separate assessment of seasonal MHW forecasts of the California Current System in eight global climate forecast systems indicated that large ensemble forecasts were potentially beneficial, with MHWs being more or less predictable depending on the forcing mechanisms ${ }^{18}$. Efforts are currently underway by the Australian Bureau of Meteorology to develop a MHW seasonal forecast system for the Australian region (Spillman and Hobday, unpublished), while ocean 'weather' forecasts (7-10 days) are already available through BLUElink, but these have not yet specifically addressed MHWs per se.

Testing and developing the aforementioned relationships and timescales for forecast systems can benefit from using data-learning algorithms, or through process-based ocean model experiments, including single-model or multi-model ensembles. Such examples have been shown for coral bleaching events ${ }^{83}$. MHW forecast systems that use large ensembles of weather and/or climate model simulations are expected to be the most promising, in line with similar ensemble numerical modelling techniques applied to forecast extreme events such as tropical cyclones. The use of machine learning to synthesise data sets is also a promising avenue towards sequential time series forecasting. For example, neural networks composed of gated recurrent units may hold promise for learning seasonal patterns in SST and predicting extremes when trained with $\mathrm{MHW}$ relevant climate features ${ }^{84}$. Data to train such models should be relevant to the phenomena being forecasted, for example the NINO3.4 index, regional sea level pressure, and upper ocean heat content. It is clear, however, that whichever method is used, forecasts systems must be developed for different regions given the spatial heterogeneity of predictability processes. 
Forecasting MHWs comes with the opportunity and challenge of communicating these forecasts with stakeholders, including fishery managers and the public ${ }^{85}$. Choosing thresholds and timescales for forecasts that are relevant to marine ecosystem response and planning requires identifying who the forecast system will inform and the desired criteria or metrics that will facilitate decision making, and will require considerable efforts toward stakeholder engagement.

409

\section{[H1] Future Perspectives}

Marine heatwaves have emerged as one of the grand challenges facing marine ecosystems and the sustainability of marine resources, demanding progress in understanding the physical phenomena; improved prediction systems; increased collaboration between marine scientists, climate scientists, marine industries and managers; and the efficient, accessible and consistent dissemination of new knowledge. We expand here on specific areas that we consider warrant attention below.

418

\section{[H2] Developing improved understanding of physical processes.}

Heat budgets provide a valuable tool for understanding processes that cause MHWs $13,14,42,48,49,74$. However, fixed-region budget approaches are limited to analysing the drivers of MHWs locally, while remote forcing, and atmospheric and oceanic teleconnections, may also be very important contributors to the development and decline of MHWs. Hence, there is merit in considering large-scale dynamical frameworks that connect remote drivers to MHW events, which may be beneficial in predicting MHW onset, persistence, decay, spatial extent, depth, and intensity. There has been some success in understanding the physical mechanisms of atmospheric heatwave development through Lagrangian back trajectory analysis ${ }^{86,87}$, a technique also used in the ocean to investigate the influences of microbial exposure to ocean temperature variability as they drift ${ }^{88}$. A useful addition for the analysis of MHW predictability may be the use of adjoint models to explain the fundamental dynamics of back trajectory teleconnections ${ }^{89}$.

\section{[H2] Marine ecosystem and fisheries management implications.}

The management of marine species, habitats, and ecosystems can be seriously affected by MHW impacts on fisheries and aquaculture, recreational activities and biodiversity conservation ${ }^{3}$. However, marine governance and management practices for responding to a rapidly changing climate are in early stages of development ${ }^{90}$, and a wider range of tools and strategies will be needed to adapt to and mitigate against future MHWs ${ }^{91}$. Although a reactive response may limit the damage to some industries, such as aquaculture, in other cases it may be too late. For example, wild abalone in a MHW would likely already be in poor condition and unable to be harvested.

Proactive responses to these extreme events - which include passive approaches such as catchment management, fishing restrictions and identification of marine protected areas can be implemented by marine managers if sufficient warning is provided ${ }^{92}$. These approaches aim to increase the resilience of marine ecosystems by limiting exposure to 
stressors that compound the impact of warming, such as overfishing, eutrophication and pollution ${ }^{93,94}$, or protecting natural ecological processes such as predation and herbivory, that confer ecosystem resistance to change ${ }^{95,96}$. However, passive approaches can be slow or inefficient ${ }^{97}$.

By contrast, active interventions seek to maintain or re-establish ecosystems or key ecosystem services through direct manipulation, ranging from habitat rehabilitation and restoration through to assisted migration, species replacements and assisted evolution ${ }^{98-}$ ${ }^{100}$. Although some of these options are ethically contentious, they may be essential for ensuring the long term survival of vulnerable marine ecosystems ${ }^{101}$ which are also under threat from increased MHWs.

The performance of many marine industries is related to the occurrence of favourable environmental conditions, including suitable habitats. Aquaculture requires water temperatures to remain within tolerance limits of the farmed species, while fisheries often rely on species that relocate in response to changing environmental conditions. Warm waters can lead to the arrival of new species, providing opportunity for commercial and recreational fishers. Marine habitats that support fisheries and tourism activities may be damaged or enhanced by anomalous conditions, with coral bleaching a well-known detrimental example. Extreme conditions such as MHWs shock systems and prevent challenges for managing economic enterprises dependent on the ocean (Box 2). Information about the likelihood of MHW occurrence is therefore valuable to a wide range of marine communities, and decisions can be made to take advantage of opportunities or minimise losses. Importantly, the availability of future environmental information can differentially advantage some groups over others, so decisions about information dissemination should be made with this in mind ${ }^{85}$. One way to minimise differences between stakeholders is to provide transparent and equitable access to information.

Experience to date suggests that three elements assist stakeholders to make the best decisions with forecasts. First, proactive planning of responses enables end users of the forecasts to weigh up different response options depending on factors such as lead time. This process can allow clear options to be considered when a forecast for undesirable conditions is issued and can be undertaken as part of business planning cycles. Second, dedicated training and information sessions are essential to understand the skill and uncertainty requirements for users ${ }^{85}$. Such sessions could potentially involve simulation activities to explore different responses to extreme events to build the capacity of stakeholders, including those from industry. Finally, implementation of risk-based responses must be considered when skill is low and uncertainty is high. For example, a forecasted MHW that might impact production could be met with a partial early harvest of the vulnerable species, rather than a full harvest ${ }^{85}$.

\section{[H2] Communication and engagement.}

While awareness about MHWs is rapidly increasing in the scientific community, much of the information can be considered technical and relatively inaccessible to stakeholders in fisheries, aquaculture, tourism and biodiversity conservation. The full potential of increased predictive capacity will be contingent on rapid dissemination and uptake across these 
relevant stakeholders. The first step towards rapid dissemination is streamlining and simplifying the information given. In this context, experience from other types of extreme events such as tropical cyclones and earthquakes shows that consistent naming conventions and intuitive classification schemes for attributing relative magnitude can be effective ${ }^{102}$. To this end, the MHW severity classification scheme ${ }^{102}$ and information provided by this approach is already seeing uptake in academic papers ${ }^{24,103}$ and websites, and we recommend that this framework be used in communicating MHWs to stakeholders. The second step towards dissemination is to generate a central repository for MHW information and news, which can serve as an interface between stakeholders and scientists. The MHW website is one such example, and other regional engagement websites are also emerging. Such initiatives should be expanded to include information targeting specific stakeholders so called targeted forecasts. Finally, using available temperature products, near real-time visualisation of ongoing MHWs allows intuitive understanding of the dynamics of near future and ongoing MHWs. Although a 'MHW tracker' is currently available in a web-based format, additional stakeholder-suited delivery mechanisms, such as smartphone applications, may be needed. With all these elements in place, predictable MHW events will allow proactive responses by potentially affected marine stakeholders, leading to improved marine management.

514

\section{[H2] Establishing baselines.}

Globally, the increased frequency of MHWs is due primarily to the warming trend ${ }^{36,104}$. It

518 has been suggested that baselines should also shift when analysing MHW events under climate change ${ }^{105}$. While using a shifting baseline period can be beneficial for analysing the underlying variability in $\mathrm{MHW}$ occurrence over time and its dynamics, ecosystem impacts from climate change are likely to be best understood if we consider changes against a fixed baseline. A baseline that shifts in line with a species' adaptive capabilities may be suitable in some cases as the impact of MHWs on marine species often critically depends on the rate of change in absolute temperature, above the species' thermal limits ${ }^{106}$. It may be that some species have no capacity to adapt on short timescales given the rapidity of temperature change, while other species can adapt either fully or perhaps partially. These differences in adaptation rate should be taken into consideration when designing baselines as fixed or shifting, and when interpreting the impacts of rapid temperature change.

On the other hand, future advances in our understanding of shifts in dynamical processes might require subsequent updates of the baseline period. One way of at least partially addressing these issues is the use of $\mathrm{MHW}$ categories ${ }^{102}$ where the introduction of new extreme categories can be considered, and analysed with respect to their drivers, even when the baseline remains fixed. Whether to fix or shift baselines depends on the key questions being asked and is the subject of ongoing discussion and debate ${ }^{105}$. It remains a fertile area for research and consideration.

\section{[H2] Keeping pace with climate change}

The rapidly growing awareness of MHWs and their increasing impact is a harbinger of the pace of climate change. In the Tasman Sea alone, three of the four summers between 2015/16 and 2018/19 have seen substantial MHWs events, two of which were driven by the 
543 presence of large and persistent high-pressure blocking events. Given that blocking events 544 are apparently becoming more frequent and pervasive as a result of climate change ${ }^{107,108}$, 545 we can expect the influence of atmospheric preconditioning to remain a critical mechanism 546 for driving large-scale and long lasting MHWs into the future.

548 Over the coming decades, MHWs will become more frequent, longer in duration and/or 549 more intense across much of the globe ${ }^{37,38}$. These projected changes represent threats to 550 the health and sustainability of marine ecosystems globally $3,109,110$. Addressing this 551 challenge will require significant action. Not only will it require coordinated global 552 commitment to reduce greenhouse gas emissions, but also governance arrangements that 553 support novel adaptation strategies, including protecting refugia for foundation marine 554 species of coral, kelp and seagrass that provide essential habitats to marine ecosystems. 555 Although skilful MHW prediction will require improved process-based understanding of 556 MHWs and their drivers, forecasting ecosystem impacts ${ }^{111}$ requires physiological 557 understanding of species' thermal sensitivity and critical thresholds and how these link to 558 other stressors. Coupling action between mitigation and adaptation will require creative 559 solutions, spanning traditional disciplinary boundaries to protect and sustain our marine 560 ecosystems and the services they provide. The utility of proactive decision-making will be 561 facilitated by skilful MHW prediction, and approaches will need to be adaptive to keep pace 562 with MHW changes in a warming world. 
1. Mills, K. E. et al. Fisheries management in a changing climate: Lessons from the 2012 ocean

2. Hughes, T. P. et al. Spatial and temporal patterns of mass bleaching of corals in the Anthropocene. Science 359, 80-83 (2018).

3. Smale, D. A. et al. Marine heatwaves threaten global biodiversity and the provision of ecosystem services. Nat. Clim. Change 9, 306-312 (2019).

4. Babcock, R. C. et al. Severe continental-scale impacts of climate change are happening now: Extreme climate events impact marine habitat forming communities along $45 \%$ of Australia's coast. Front. Mar. Sci. 6, (2019).

5. Garrabou, J. et al. Mass mortality in Northwestern Mediterranean rocky benthic communities: Effects of the 2003 heat wave. Glob. Chang. Biol. 15, 1090-1103 (2009).

6. Benthuysen, J. A., Oliver, E. C., Chen, K. \& Wernberg, T. Advances in understanding marine heatwaves and their impacts. Front. Mar. Sci. (2020). doi:10.3389/fmars.2020.00147

7. Wernberg, T. et al. Climate-driven regime shift of a temperate marine ecosystem. Science 353, 169-172 (2016).

8. Wernberg, T. Marine heatwave drives collapse of kelp forests in Western Australia. in Ecological Studies (eds. Canadell, J. G. \& Jackson, R. B.) (Springer-Nature, 2019).

9. Pearce, A. et al. The "marine heat wave" off Western Australia during the summer of 2010/11. Fisheries Research Report No. 222. Department of Fisheries, Western Australia. Fisheries Research (2011). doi:55 689794771

10. Olita, A. et al. Effects of the 2003 European heatwave on the Central Mediterranean Sea: surface fluxes and the dynamical response. Ocean Sci. 3, 273-289 (2007).

11. Pearce, A. F. \& Feng, M. The rise and fall of the 'marine heat wave' off Western Australia during the summer of 2010/2011. J. Mar. Syst. 111-112, 139-156 (2013).

12. Chen, K., Gawarkiewicz, G. G., Lentz, S. J. \& Bane, J. M. Diagnosing the warming of the northeastern U.S. coastal ocean in 2012: A linkage between the atmospheric jet stream variability and ocean response. J. Geophys. Res. Ocean. 119, 218-227 (2014).

13. Oliver, E. C. J. et al. The unprecedented 2015/16 Tasman Sea marine heatwave. Nat. Commun. 8, (2017).

14. Holbrook, N. J. et al. A global assessment of marine heatwaves and their drivers. Nat. Commun. 10, (2019).

15. Di Lorenzo, E. \& Mantua, N. Multi-year persistence of the $2014 / 15$ North Pacific marine heatwave. Nat. Clim. Change 6, 1042-1047 (2016).

16. Jackson, J. M., Johnson, G. C., Dosser, H. V. \& Ross, T. Warming from recent marine heatwave lingers in deep British Columbia fjord. Geophys. Res. Lett. 45, 9757-9764 (2018).

17. Reed, D. et al. Extreme warming challenges sentinel status of kelp forests as indicators of climate change. Nat. Commun. 7, (2016).

18. Jacox, M., Tommasi, D., Alexander, M., Hervieux, G. \& Stock, C. Predicting the evolution of the 2014-16 California Current System marine heatwave from an ensemble of coupled global climate forecasts. Front. Mar. Sci. 6, (2019).

19. Lee, T. et al. Record warming in the South Pacific and western Antarctica associated with the strong central-Pacific El Niño in 2009-10. Geophys. Res. Lett. 37, 1-6 (2010).

20. Benthuysen, J. A., Oliver, E. C. J., Feng, M. \& Marshall, A. G. Extreme marine warming across tropical Australia during austral summer 2015-2016. J. Geophys. Res. Ocean. 123, 1301-1326 (2018).

21. Eakin, C. M., Sweatman, H. P. A. \& Brainard, R. E. The 2014-2017 global-scale coral bleaching event: insights and impacts. Coral Reefs 38, 539-545 (2019).

22. Gurgel, C. F. D., Camacho, O., Minne, A. J. P., Wernberg, T. \& Coleman, M. A. Marine heatwave drives cryptic loss of genetic diversity in underwater forests. Curr. Biol. 30, 1199- 
1206 (2020).

615

616

617

618

619

620

621

622

623

624

625

626

627

628

629

630

631

632

633

634

635

636

637

638

639

640

641

642

643

644

645

646

647

648

649

650

651

652

653

654

655

656

657

658

659

660

661

662

663

664

23. Caputi, N. et al. Management adaptation of invertebrate fisheries to an extreme marine heat wave event at a global warming hotspot. Ecol. Evol. 6, 3583-3593 (2016). doi:10.1002/ece3.2137

24. Caputi, N. et al. Factors affecting the recovery of invertebrate stocks from the 2011 Western Australian extreme marine heatwave. Front. Mar. Sci. 6, (2019).

25. Caputi, N. et al. Management implications of climate change effect on fisheries in Western Australia, Part 2: Case studies. Fisheries Research Report No. 261 (2014).

26. Hughes, T. P. et al. Global warming and recurrent mass bleaching of corals. Nature 543, 373377 (2017).

27. Wernberg, T. et al. An extreme climatic event alters marine ecosystem structure in a global biodiversity hotspot. Nat. Clim. Change 3, 78-82 (2013).

28. Thomsen, M. S. et al. Local extinction of bull kelp (Durvillaea spp.) due to a marine heatwave. Front. Mar. Sci. 6, (2019).

29. Arafeh-Dalmau, N. et al. Extreme marine heatwaves alter kelp forest community near its equatorward distribution limit. Front. Mar. Sci. 6, (2019).

30. Filbee-Dexter, K. et al. Marine heatwaves and the collapse of North Atlantic kelp forests. Proc. R. Soc. B Biol. Sci. (2020).

31. Arias-Ortiz, A. et al. A marine heatwave drives massive losses from the world's largest seagrass carbon stocks. Nat. Clim. Change 8, 338-344 (2018). doi:10.1038/s41558-018-0096y

32. Zisserson, B. \& Cook, A. Impact of bottom water temperature change on the southernmost snow crab fishery in the Atlantic Ocean. Fish. Res. 195, 12-18 (2017).

33. Caputi, N., Jackson, G. \& Pearce, A. The marine heat wave off Western Australia during the summer of 2010/11 - 2 years on. (2014).

34. Cavole, L. M. et al. Biological Impacts of the 2013-2015 warm-water anomaly in the northeast Pacific. Oceanography 29, 273-285 (2016).

35. Santora, J. A. et al. Habitat compression and ecosystem shifts as potential links between marine heatwave and record whale entanglements. Nat. Commun. 11, (2020).

36. Oliver, E. C. J. et al. Longer and more frequent marine heatwaves over the past century. Nat. Commun. 9, (2018).

37. Frölicher, T. L., Fischer, E. M. \& Gruber, N. Marine heatwaves under global warming. Nature 560, 360-364 (2018).

38. Oliver, E. C. J. et al. Projected marine heatwaves in the 21st Century and the potential for ecological impact. Front. Mar. Sci. 6, (2019).

39. Bond, N. A., Cronin, M. F., Freeland, H. \& Mantua, N. Causes and impacts of the 2014 warm anomaly in the NE Pacific. Geophys. Res. Lett. 42, 3414-3420 (2015).

40. Rodrigues, R. R., Taschetto, A. S., Sen Gupta, A. \& Foltz, G. R. Common cause for severe droughts in South America and marine heatwaves in the South Atlantic. Nat. Geosci. 12, 620626 (2019).

41. Black, E., Blackburn, M., Harrison, R. G., Hoskins, B. J. \& Methven, J. Factors contributing to the summer 2003 European heatwave. Weather 59, 217-223 (2004).

42. Chen, K., Gawarkiewicz, G., Kwon, Y.-O. \& Zhang, W. The role of atmospheric forcing versus ocean advection during the extreme warming of the Northeast U.S. continental shelf in 2012. J. Geophys. Res. Ocean. 120, 4324-4339 (2015).

43. Salinger, M. J. et al. The unprecedented coupled ocean-atmosphere summer heatwave in the New Zealand region 2017/18: Drivers, mechanisms and impacts. Environ. Res. Lett. 14, (2019).

44. Perkins-Kirkpatrick, S. E. et al. The role of natural variability and anthropogenic climate change in the 2017/18 Tasman Sea marine heatwave. Bull. Am. Meteorol. Soc. 100, S105S110 (2019). 
45. Sparnocchia, S., Schiano, M. E., Picco, P., Bozzano, R. \& Cappelletti, A. The anomalous warming of summer 2003 in the surface layer of the Central Ligurian Sea (Western Mediterranean). Ann. Geophys. 24, 443-452 (2006).

46. Swain, D. The extraordinary California dry spell continues: 2013 will probably be the driest year on record. California Weather Blog, Weather West (2013).

47. Alexander, M. A., Deser, C. \& Timlin, M. S. The reemergence of SST anomalies in the North Pacific Ocean. J. Clim. 12, 2419-2433 (1999).

48. Benthuysen, J., Feng, M. \& Zhong, L. Spatial patterns of warming off Western Australia during the 2011 Ningaloo Niño: Quantifying impacts of remote and local forcing. Cont. Shelf Res. 91, 232-246 (2014).

49. Kataoka, T., Tozuka, T. \& Yamagata, T. Generation and decay mechanisms of Ningaloo Niño/Niña. J. Geophys. Res. Ocean. 122, 8913-8932 (2017).

50. Behrens, E., Fernandez, D. \& Sutton, P. Meridional oceanic heat transport influences marine heatwaves in the Tasman Sea on interannual to decadal timescales. Front. Mar. Sci. 6, (2019).

51. Scannell, H. A., Pershing, A. J., Alexander, M. A., Thomas, A. C. \& Mills, K. E. Frequency of marine heatwaves in the North Atlantic and North Pacific since 1950. Geophys. Res. Lett. 43, (2016).

52. Hartmann, D. L. Pacific sea surface temperature and the winter of 2014. Geophys. Res. Lett. 42, 1894-1902 (2015).

53. Marshall, A. G. \& Hendon, H. H. Impacts of the MJO in the Indian Ocean and on the Western Australian coast. Clim. Dyn. 42, 579-595 (2014).

54. Zhang, N., Feng, M., Hendon, H. H., Hobday, A. J. \& Zinke, J. Opposite polarities of ENSO drive distinct patterns of coral bleaching potentials in the southeast Indian Ocean. Sci. Rep. 7, 2443 (2017).

55. Kataoka, T., Tozuka, T., Yamagata, T. \& Swadhin Behera. On the Ningaloo Niño/Niña. Clim. Dyn. (2013). doi:10.1007/s00382-013-1961-z

56. Holbrook, N. J., Goodwin, I. D., McGregor, S., Molina, E. \& Power, S. B. ENSO to multi-decadal time scale changes in East Australian Current transports and Fort Denison sea level: Oceanic Rossby waves as the connecting mechanism. Deep. Res. Part II Top. Stud. Oceanogr. 58, 547558 (2011).

57. Li, Z., Holbrook, N. J., Zhang, X., Oliver, E. C. J. \& Cougnon, E. A. Remote forcing of Tasman Sea marine heatwaves. J. Clim. 33, 5337-5354 (2020). doi:10.1175/jcli-d-19-0641.1

58. Schaeffer, A. \& Roughan, M. Subsurface intensification of marine heatwaves off southeastern Australia: The role of stratification and local winds. Geophys. Res. Lett. 44, 5025-5033 (2017).

59. Elzahaby, Y. \& Schaeffer, A. Observational Insight Into the subsurface anomalies of marine heatwaves. Front. Mar. Sci. 6, (2019).

60. Ridgway, K. R., Dunn, J. R. \& Wilkin, J. L. Ocean interpolation by four-dimensional weighted least squares - Application to the waters around Australasia. J. Atmos. Ocean. Technol. 19, 1357-1375 (2002).

61. Roemmich, D. \& Gilson, J. The 2004-2008 mean and annual cycle of temperature, salinity, and steric height in the global ocean from the Argo Program. Prog. Oceanogr. 82, 81-100 (2009).

62. Moltmann, T. The "costal data paradox". Journal of Ocean Technology 13, 148-149 (2018).

63. Oliver, E. C. J. et al. Marine heatwaves off eastern Tasmania: Trends, interannual variability, and predictability. Prog. Oceanogr. 161, (2018).

64. Darmaraki, S. et al. Future evolution of marine heatwaves in the Mediterranean Sea. Clim. Dyn. 53, 1371-1392 (2019).

65. Schlegel, R. W., Oliver, E. C. J., Hobday, A. J. \& Smit, A. J. Detecting marine heatwaves with sub-optimal data. Front. Mar. Sci. 6, (2019).

66. Salinger, J. et al. Decadal-scale forecasting of climate drivers for marine applications. 74, 1-68 (2016).

67. Dunstan, P. K. et al. How can climate predictions improve sustainability of coastal fisheries in 
Pacific Small-Island Developing States? Mar. Policy 88, 295-302 (2018). doi:10.1016/j.marpol.2017.09.033

68. Smith, G. \& Spillman, C. New high-resolution sea surface temperature forecasts for coral reef management on the Great Barrier Reef. Coral Reefs 38, 1039-1056 (2019).

69. White, C. J. et al. Potential applications of subseasonal-to-seasonal (S2S) predictions. Meteorol. Appl. 24, (2017).

70. Hobday, A. J., Spillman, C. M., Paige Eveson, J. \& Hartog, J. R. Seasonal forecasting for decision support in marine fisheries and aquaculture. Fish. Oceanogr. 25, 45-56 (2016).

71. Game, E. T., Watts, M. E., Wooldridge, S. \& Possingham, H. P. Planning for persistence in marine reserves: A question of catastrophic importance. Ecol. Appl. 18, 670-680 (2008).

72. Johnson, C. R., Chabot, R. H., Marzloff, M. P. \& Wotherspoon, S. Knowing when (not) to attempt ecological restoration. Restor. Ecol. 25, 140-147 (2017).

73. Tommasi, D. et al. Managing living marine resources in a dynamic environment: The role of seasonal to decadal climate forecasts. Prog. Oceanogr. 152, 15-49 (2017).

74. Marshall, A. G., Hendon, H. H., Feng, M. \& Schiller, A. Initiation and amplification of the Ningaloo Niño. Clim. Dyn. 45, 2367-2385 (2015). doi:10.1007/s00382-015-2477-5

75. D'Andrea, F. et al. Northern Hemisphere atmospheric blocking as simulated by 15 atmospheric general circulation models in the period 1979-1988. Clim. Dyn. 14, 385-407 (1998).

76. Scaife, A. A., Woollings, T., Knight, J., Martin, G. \& Hinton, T. Atmospheric blocking and mean biases in climate models. J. Clim. 23, 6143-6152 (2010).

77. Davini, P. \& D'Andrea, F. Northern Hemisphere atmospheric blocking representation in global climate models: Twenty years of improvements? J. Clim. 29, 8823-8840 (2016).

78. Kwon, Y. O., Camacho, A., Martinez, C. \& Seo, H. North Atlantic winter eddy-driven jet and atmospheric blocking variability in the Community Earth System Model version 1 Large Ensemble simulations. Clim. Dyn. 51, 3275-3289 (2018).

79. Pilo, G. S., Mata, M. M. \& Azevedo, J. L. L. Eddy surface properties and propagation at Southern Hemisphere western boundary current systems. Ocean Sci. 11, 629-641 (2015).

80. Oliver, E. C. J., Wotherspoon, S. J., Chamberlain, M. A. \& Holbrook, N. J. Projected Tasman Sea extremes in sea surface temperature through the twenty-first century. J. Clim. 27, 1980-1998 (2014).

81. Oliver, E. C. J., O'Kane, T. J. \& Holbrook, N. J. Projected changes to Tasman Sea eddies in a future climate. J. Geophys. Res. Ocean. 120, 7150-7165 (2015).

82. Hu, Z. Z., Kumar, A., Jha, B., Zhu, J. \& Huang, B. Persistence and predictions of the remarkable warm anomaly in the northeastern Pacific ocean during 2014-16. J. Clim. 30, 689-702 (2017).

83. Spillman, C. M. Operational real-time seasonal forecasts for coral reef management. J. Oper. Oceanogr. 4, 13-22 (2011).

84. Yang, Y. et al. A CFCC-LSTM Model for Sea Surface Temperature Prediction. IEEE Geosci. Remote Sens. Lett. 15, 207-211 (2018).

85. Hobday, A. J. et al. Ethical considerations and unanticipated consequences associated with ecological forecasting for marine resources. ICES J. Mar. Sci. (2019). doi:10.1093/icesjms/fsy210

86. Quinting, J. F. \& Reeder, M. J. Southeastern Australian heat waves from a trajectory viewpoint. Mon. Weather Rev. 145, 4109-4125 (2017).

87. Quinting, J. F., Parker, T. J. \& Reeder, M. J. Two synoptic routes to subtropical heat waves as illustrated in the Brisbane region of Australia. Geophys. Res. Lett. 45, 10,700-10,708 (2018).

88. Doblin, M. A. \& Van Sebille, E. Drift in ocean currents impacts intergenerational microbial exposure to temperature. Proc. Natl. Acad. Sci. U. S. A. 113, 5700-5705 (2016).

89. Zhang, X., Cornuelle, B. \& Roemmich, D. Sensitivity of western boundary transport at the mean north equatorial current bifurcation latitude to wind forcing. J. Phys. Oceanogr. 42, 2056-2072 (2012). 
90. Pecl, G. T. et al. Autonomous adaptation to climate-driven change in marine biodiversity in a global marine hotspot. Ambio 48, 1498-1515 (2019).

91. Serrao-Neumann, S. et al. Marine governance to avoid tipping points: Can we adapt the adaptability envelope? Mar. Policy 65, 56-67 (2016).

92. Hobday, A. J. et al. A framework for combining seasonal forecasts and climate projections to aid risk management for fisheries and aquaculture. Front. Mar. Sci. 5, (2018).

93. Wernberg, T. et al. Impacts of climate change in a global hotspot for temperate marine biodiversity and ocean warming. J. Exp. Mar. Biol. Ecol. 400, 7-16 (2011).

94. Strain, E. M. A., Thomson, R. J., Micheli, F., Mancuso, F. P. \& Airoldi, L. Identifying the interacting roles of stressors in driving the global loss of canopy-forming to mat-forming algae in marine ecosystems. Glob. Chang. Biol. 20, 3300-3312 (2014).

95. Bates, A. E. et al. Resilience and signatures of tropicalization in protected reef fish communities. Nat. Clim. Change 4, 62-67 (2014).

96. Connell, S. D. \& Ghedini, G. Resisting regime-shifts: The stabilising effect of compensatory processes. Trends in Ecology and Evolution 30, 513-515 (2015).

97. Bruno, J. F., Côté, I. M. \& Toth, L. T. Climate change, coral loss, and the curious case of the Parrotfish paradigm: Why don't marine protected areas improve reef resilience? Ann. Rev. Mar. Sci. 11, 307-334 (2019).

98. Coleman, M. A. \& Goold, H. D. Harnessing synthetic biology for kelp forest conservation1. J. Phycol. 55, 745-751 (2019).

99. Vergés, A. et al. Tropicalisation of temperate reefs: Implications for ecosystem functions and management actions. Funct. Ecol. 33, 1000-1013 (2019).

100. Wernberg, T., Krumhansl, K., Filbee-Dexter, K. \& Pedersen, M. F. Status and trends for the world's kelp forests. In World Seas: an Environmental Evaluation 57-78 (2019). doi:10.1016/b978-0-12-805052-1.00003-6

101. Filbee-Dexter, K. \& Smajdor, A. Ethics of assisted evolution in marine conservation. Front. Mar. Sci. 6, (2019).

102. Hobday, A. J. et al. Categorizing and naming marine heatwaves. Oceanography 31, 162-173 (2018).

103. Chandrapavan, A., Caputi, N. \& Kangas, M. I. The decline and recovery of a crab population from an extreme marine heatwave and a changing climate. Front. Mar. Sci. 6, (2019).

104. Oliver, E. C. J. Mean warming not variability drives marine heatwave trends. Clim. Dyn. 53, 1653-1659 (2019).

105. Jacox, M. G. Marine heatwaves in a changing climate. Nature 571, 485-487 (2019).

106. Vinagre, C. et al. Upper thermal limits and warming safety margins of coastal marine species - Indicator baseline for future reference. Ecol. Indic. 102, 644-649 (2019).

107. Nakamura, N. \& Huang, C. S. Y. Atmospheric blocking as a traffic jam in the jet stream. Science 361, 42-47 (2018).

108. Mann, M. E. et al. Projected changes in persistent extreme summer weather events: The role of quasi-resonant amplification. Sci. Adv. 4, (2018).

109. Straub, S. C. et al. Resistance, extinction, and everything in between - The diverse responses of seaweeds to marine heatwaves. Frontiers in Marine Science 6, (2019).

110. Frölicher, T. L. \& Laufkötter, C. Emerging risks from marine heat waves. Nature Communications 9, (2018).

111. Jacox, M. G. et al. Seasonal-to-interannual prediction of North American coastal marine ecosystems: Forecast methods, mechanisms of predictability, and priority developments. Prog. Oceanogr. 183, (2020).

112. Feng, M., McPhaden, M. J., Xie, S. P. \& Hafner, J. La Niña forces unprecedented Leeuwin Current warming in 2011. Sci. Rep. 3, 1-9 (2013).

113. Gammelsrød, T., Bartholomae, C. H., Boyer, D. C., Filipe, V. L. L. \& O’Toole, M. J. Intrusion of warm surface water along the Angolan-Namibian coast in February-March 1995: the 1995 
Benguela Niño. South African J. Mar. Sci. 19, 41-56 (1998).

114. Spencer, T., Teleki, K. A., Bradshaw, C. \& Spalding, M. D. Coral bleaching in the Southern Seychelles during the 1997-1998 Indian Ocean warm event. Mar. Pollut. Bull. 40, 569-586 (2000).

115. McPhaden, M. J. Genesis and evolution of the 1997-98 El Niño. Science 283, 950-954 (1999).

116. Vivekanandan, E., Hussain Ali, M., Jasper, B. \& Rajagopalan, M. Thermal thresholds for coral bleaching in the Indian seas. J. Mar. Biol. Assoc. India 50, 209-214 (2008).

117. Krishnan, P. et al. Elevated sea surface temperature during May 2010 induces mass bleaching of corals in the Andaman. Curr. Sci. 100, 111-117 (2011).

118. Collins, M. et al. Extremes, abrupt changes and managing risks. in IPCC Special Report on the Ocean and Cryosphere in a Changing Climate, 589-655 (2019).

119. Frölicher, T. L. Extreme climatic events in the ocean. In Predicting Future Oceans 53-60 (2019). doi:10.1016/b978-0-12-817945-1.00005-8

120. Rayner, N. A. et al. Global analyses of sea surface temperature, sea ice, and night marine air temperature since the late nineteenth century. J. Geophys. Res. Atmos. 108, (2003).

121. Huang, B. et al. Extended reconstructed sea surface temperature, Version 5 (ERSSTV5): Upgrades, validations, and intercomparisons. J. Clim. 30, 8179-8205 (2017).

122. Hirahara, S., Ishii, M. \& Fukuda, Y. Centennial-scale sea surface temperature analysis and its uncertainty. J. Clim. 27, 57-75 (2014).

123. Laloyaux, P., Balmaseda, M., Dee, D., Mogensen, K. \& Janssen, P. A coupled data assimilation system for climate reanalysis. Q. J. R. Meteorol. Soc. 142, 65-78 (2016).

124. Giese, B.S., Seidel, H.F., Compo, G.P. \& Sardeshmukh, P. D. An ensemble of ocean reanalyses for 1815-2013 with sparse observational input. J. Geophys. Res. Ocean. 121, 6891-6910 (2016).

125. Hobday, A. J. et al. A hierarchical approach to defining marine heatwaves. Prog. Oceanogr. 141, 227-238 (2016).

126. Wijffels, S. E. et al. A fine spatial-scale sea surface temperature atlas of the Australian regional seas (SSTAARS): Seasonal variability and trends around Australasia and New Zealand revisited. J. Mar. Syst. 187, 156-196 (2018).

127. Perkins, S. E. \& Alexander, L. V. On the measurement of heat waves. J. Clim. 26, 4500-4517 (2013).

128. Pershing, A. J. et al. Challenges to natural and human communities from surprising ocean temperatures. Proc. Natl. Acad. Sci. U. S. A. 116, 18378-18383 (2019).

\section{Acknowledgements}

. N.J.H. acknowledges support from the Australian Research Council Centre of Excellence for Climate Extremes (grant CE170100023) and the Australian Government National Environmental Science Programme (NESP) Earth Systems and Climate Change (ESCC) Hub (Project 5.8). D.A.S. was supported by a UKRI Future Leaders Fellowship (MR/S032827/1). T.W. also acknowledges support from the ARC for MHW work (DP170100023). J. A. B. was supported through the NESP Tropical Water Quality (TWQ) Hub (Project 4.2).

\section{Author contributions}

N.J.H. led the overall conceptual design, led the activity and coordinated the writing. A.S.G. generated Figures 1, 3 and 5. E.C.J.O. generated Figure 2. J.A.B. generated Figure 4. A.J.H. led the conceptual design for Box 2 and Table 1. All authors (N.J.H., A.S.G., E.C.J.O., A.J.H., 
J.A.B., H.A.S., D.A.S. and T.W.) discussed the concepts presented and contributed to the

867 writing.

868

869

870

\section{Competing interests}

871 The authors declare no competing interests.

872

873

\section{Peer review information}

874

875

Nature Reviews Earth \& Environment thanks Jennifer Jackson and the other, anonymous, reviewer(s) for their contribution to the peer review of this work.

878

879

880

\section{Publisher's note}

Springer Nature remains neutral with regard to jurisdictional claims in published maps and 882 institutional affiliations. 
885 Table 1 | Mechanisms and timescales influencing the predictability of MHW likelihood

\begin{tabular}{|c|c|c|c|c|}
\hline & $\begin{array}{c}\text { Strong } \\
\text { atmospheric } \\
\text { and oceanic } \\
\text { contributions* }\end{array}$ & $\begin{array}{c}\text { Strong } \\
\text { atmospheric } \\
\text { and weak } \\
\text { oceanic } \\
\text { contributions* }\end{array}$ & $\begin{array}{c}\text { Weak } \\
\text { atmospheric } \\
\text { and strong } \\
\text { oceanic } \\
\text { contributions* }\end{array}$ & $\begin{array}{c}\text { Weak } \\
\text { atmospheric } \\
\text { and oceanic } \\
\text { contributions* }\end{array}$ \\
\hline $\begin{array}{l}\text { Predictability } \\
\text { lead time }\end{array}$ & $\begin{array}{l}\text { Months (at } \\
\text { least) }\end{array}$ & $\begin{array}{l}\sim 1-2 \text { weeks or } \\
\text { season ahead }\end{array}$ & $\begin{array}{l}\text { Months to } \\
\text { years }\end{array}$ & Days \\
\hline $\begin{array}{l}\text { Predictability } \\
\text { source }\end{array}$ & $\begin{array}{l}\text { Local and } \\
\text { remote climate } \\
\text { forcing }\end{array}$ & $\begin{array}{l}\text { Atmospheric } \\
\text { preconditioning } \\
\text { and/or } \\
\text { teleconnections }\end{array}$ & $\begin{array}{l}\text { Oceanic } \\
\text { preconditioning } \\
\text { and/or } \\
\text { teleconnections }\end{array}$ & $\begin{array}{l}\text { Transitory } \\
\text { weather or } \\
\text { eddies }\end{array}$ \\
\hline Persistence & Months & Months & Months & Hours to days \\
\hline Vertical scale & Up to $100 \mathrm{~s} m$ & Up to $10 \mathrm{~s} \mathrm{~m}$ & Up to $100 \mathrm{~s} m$ & Up to $10 \mathrm{~s} \mathrm{~m}$ \\
\hline Horizontal scale & $1000 \mathrm{~s} \mathrm{~km}$ & $1000 \mathrm{~s} \mathrm{~km}$ & $100 \mathrm{~s} \mathrm{~km}$ & Local \\
\hline $\begin{array}{l}\text { Impacted } \\
\text { ecosystems }\end{array}$ & $\begin{array}{l}\text { Surface to } \\
\text { benthic }\end{array}$ & $\begin{array}{l}\text { Within mixed } \\
\text { layer }\end{array}$ & $\begin{array}{l}\text { Surface to } \\
\text { benthic }\end{array}$ & Minimal \\
\hline Impact severity & $\begin{array}{l}\text { Potentially } \\
\text { substantial }\end{array}$ & $\begin{array}{l}\text { Moderate to } \\
\text { substantial }\end{array}$ & $\begin{array}{l}\text { Moderate to } \\
\text { substantial }\end{array}$ & Minor \\
\hline Example & $\begin{array}{l}2011 \text { Western } \\
\text { Australia MHW } \\
48,112\end{array}$ & 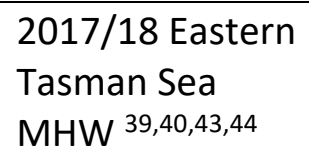 & $\begin{array}{l}\text { 2015/16 } \\
\text { Tasman Sea } \\
\text { MHW 13,50,57 }\end{array}$ & Heat spikes \\
\hline
\end{tabular}

886 *contributions refer to those from local atmospheric sources and those arising from oceanic 887 advection 
FIGURE 1 | Drivers and ecological impacts of major MHW events. A subset of major MHW events since 1995. The MHW intensity scale, from moderate to extreme, represents conditions corresponding to the peak date of the event, with categories identified successively as multiples of the $90^{\text {th }}$ percentile ${ }^{102}$. This figure highlights the spatial scale, intensity and ecological impacts of significant MHW events around the world, including Benguela Niño ${ }^{113}$; Seychelles ${ }^{114}$; Ningaloo Niño ${ }^{27,112}$; Tasman Sea ${ }^{13}$; central South Pacific 19; South Atlantic ${ }^{40}$; 1997/98 El Niño ${ }^{115}$; northwest Atlantic ${ }^{1,12}$; The Blob ${ }^{15,39}$; Bay of Bengal 116,117 and the Mediterranean Sea ${ }^{10,45}$. This figure is inspired by schematics in Refs ${ }^{110,118,119}$. *While the Bay of Bengal MHW co-occurred with a major central Pacific El Niño event, there have been no studies to confirm or deny a causal link.

910

911

912

913

FIGURE 2 | Trends in global MHW occurrence. a| Globally averaged changes in the annual number of MHW days based on the Hadley Centre Sea Ice and Sea Surface Temperature (HadISST) ${ }^{120}$, Extended Reconstructed Sea Surface Temperature (ERSST) ${ }^{121}$, COBE ${ }^{122}$, CERA20C ${ }^{123}$, and Simple Ocean Data Assimilation (SODA) datasets ${ }^{124}$. Grey shading indicates the $95 \%$ confidence interval b| Changes in the annual number of MHW days from the period 1925-1954 to 1987-2016, based on the same data as in panel a. Hatching indicates statistically significant changes $(p<0.05) \mathrm{c}$ Changes in the annual number of MHW days from the period 1961-1990 to 2031-2060, based on 6 Climate Model Intercomparison Project (CMIP5) global climate models under the Representative Concentration Pathway (RCP8.5) emissions scenario. Hatching indicates grid points in which all 6 models agree on the sign of the change. Grey areas in $\mathbf{b}$ and $\mathbf{c}$ reflect missing data, primarily due to seasonal ice cover. In panels $\mathbf{a}$ and $\mathbf{b}$, the effect of natural variability (the Atlantic Multidecadal Oscillation (AMO), PDO and ENSO) has been removed following ref ${ }^{36}$. MHW days are defined as the number of days when SST anomalies exceed a daily climatological $90^{\text {th }}$ percentile threshold, for at least 5 days ${ }^{125}$. The annual count of MHW days has increased substantially since the early $20^{\text {th }}$ century and this increase has only accelerated up to the present day. This rise is projected to continue increasing in the future, with annual MHW days approaching a full year by the late $21^{\text {st }}$ century. Panel a adapted with permission from ref ${ }^{36}$. Panel $\mathrm{c}$ adapted with permission from ref ${ }^{38}$.

FIGURE 3 | Marine heatwave drivers and impacts. Schematic showing the drivers of MHWs (left) and their impacts on oceanic and coastal ecosystems (right). Surface MHWs are caused by local ocean and atmosphere heat fluxes affecting the surface mixed layer. These processes are controlled by local synoptic systems that can be modulated by large-scale climate oscillations and anthropogenic warming. Impacts range across trophic levels often affecting human systems. ENSO: EI Niño-Southern Oscillation, IPO: Interdecadal Pacific Oscillation, MJO: Madden-Julian Oscillation, NAO: North Atlantic Oscillation, H: high pressure. 

mean SST anomalies during the 2018/19 Tasman Sea MHW. SST represents monthly-mean, multi-sensor, night-time only readings at $0.2 \mathrm{~m}$ depth, obtained from the Integrated Marine Observing System (IMOS). The SST product is available from the Australian Ocean Data Network (AODN) Portal (https://portal.aodn.org.au/). Anomalies are calculated with respect to the $50^{\text {th }}$ percentile February climatology from the Sea Surface Temperature Atlas of Australian Regional Seas (SSTAARS ${ }^{126}$ ). b| February 2019 SST percentiles based on SSTAARS, where the percentiles are centred on mid-February and constructed over 60-days. The region off eastern Tasmania is shown with a white box. c| Subsurface temperature measured by a Slocum glider, deployed 13 February 2019 in the north and recovered 9 March 2019 in the south, as part of the IMOS Event Based Sampling sub-facility. The Slocum glider data are available from the AODN Portal and collected as part of the IMOS Event Based Sampling sub-facility and the Australian National Facility for Ocean Gliders (ANFOG). Bathymetry data off Tasmania were sourced from the Geoscience Australia product "Australian bathymetry and Topography, June 2009" (https://ecat.ga.gov.au/geonetwork/srv/eng/catalog.search\#/metadata/67703). Coastline data were sourced from the Global Self-Consistent, Hierarchical, High-resolution Geography Database (GSHHG) version 2.3.6 (http://www.soest.hawaii.edu/pwessel/gshhg/). The temperatures and ocean current velocities (sub-sampled) along $40.8^{\circ} \mathrm{S}$ and along $155 \mathrm{~m}$ depth are the 13 - 28 February 2019 mean derived from the $10 \mathrm{~km}$ Bluelink Re-Analysis (BRAN)-2015. The BRAN-2015 product is from the National Computational Infrastructure at: http://dapds00.nci.org.au/thredds/catalog/gb6/BRAN/catalog.html. The current velocities are shaded according to their depth, and consistent with the shading of isobaths plotted every $50 \mathrm{~m}$ (black to light grey).

FIGURE 5 | Marine heatwave potential predictability and forecast timescales. A spectrum of MHW prediction timescales and types ranging from initialised forecasts, which predict specific events (deterministic forecasts), through to externally forced projections, in which scenarios can be used to explore changed statistical probabilities of MHW likelihoods (statistical forecasts). The red horizontal bars provide indicative timescales of predictability for each prediction system type, where increasing opacity corresponds to increasing confidence in the prediction skill for that lead time. ENSO: El Niño-Southern Oscillation, IOD: Indian Ocean Dipole, WBC: Western boundary currents.

969 Images Box 2 | Figure, part a, roe's abalone: image courtesy of anthony Hart, DPirD970 Mollusc science; part b Maine lobster: image courtesy of andrew Pershing- Gulf, Maine 971 research institute; part c Cassin's auklets: image courtesy of L. Doyle/COasst, Julia Parrish. 
'Heatwave' is a well-recognised term, broadly indicating to society the risks associated with thermal stresses on people and the environment. The atmospheric research community uses qualitative descriptors and quantitative metrics to express heatwave events, with a widely-used definition describing a heatwave as at least 3 consecutive days of air temperatures above the $90^{\text {th }}$ percentile of climatological, seasonally varying norms ${ }^{127}$. In 2015, an analogous definition was developed for marine heatwaves (MHWs). Compared to the atmospheric definition, it was recommended that a threshold of at least 5 days above the seasonally-varying $90^{\text {th }}$ percentile ${ }^{125}$ is needed to acknowledge longer thermal persistence timescales in the ocean. MHWs have also been defined as sea surface temperatures (SSTs) exceeding the $99^{\text {th }}$ percentile ${ }^{37,110}-$ a definition applied in the IPCC Special Report on the Ocean and Cryosphere (SROCC ${ }^{118}$ ). In fact, SROCC defines a MHW as 'an event at a particular place and time of the year that is rare and predominately, but not exclusively, defined with a relative threshold; that is, an event rarer than 90th or 99th percentile of a probability density function.'

988

\section{Box 2: MHWs as a stress test for management systems}

Three well known MHWs challenged existing management approaches, due to their intensity, duration and rapid onset. The 2011 Western Australia MHW resulted in mass mortality of Roes' abalone, and in response, managers closed the fishery and instituted an outplanting approach in the years following the event. Scallop fisheries in the region affected by the MHW were closed for 3-5 years, while the Shark Bay crab fishery was closed for 18 months ${ }^{24}$. This event tested assessment and management responses and showed that flexible harvest strategies allowed for early management intervention ${ }^{24}$. This was aided by early detection of the MHW, monitoring of the immediate effects on the ecosystem, and rapid assessment of likely impacts on fishery stocks - based on a thorough understanding of the regional fishery-environment relationships ${ }^{24}$. The 2012 Gulf of Maine MHW revealed unexpected connections between the natural and human components of the ecosystem ${ }^{128}$. Early and above-average landings in a valuable lobster fishery led to a backlog in the supply chain and a drop in lobster price; exacerbating the supply chain bottleneck was the fact that the Canadian lobster fishery also had unusually high spring landings. The joint impact was low prices on both sides of the border, accompanied by Canadian protests and blockades of lobster imports coming from Maine. The management system was unable to respond to the 2012 event, but made changes that meant another MHW in 2016 did not cause the same impacts. These changes included the development of seasonal forecasting approaches to provide warning to future events. A large MHW in the northeast Pacific (the "Blob") appeared off the coast of Alaska in the winter of 2013-2014 and subsequently stretched south to Baja California. This event persisted through to the end of 2015. Mass strandings of marine mammals and seabirds occurred along the west coast of the United States and Canada ${ }^{34}$. Several thousand California sea lions died on beaches following shortages of forage fish. More than 50,000 Cassin's auklets were estimated to have starved and washed 
1018 ashore beginning in September 2014. These dying and dead animals stressed animal rescue 1019 arrangements, pathology testing, and management responses. All the examples of MHWs

1020 above required rapid and novel responses, which can be difficult if policy or legislative 1021 barriers exist. In the cases where flexible instruments were already in place, such as in 1022 Western Australia, the management system coped better, even under persistent impacts. In 1023 other cases, improvements were not realised until the next event. Learning from these 1024 stress tests will improve management under climate variability and change, and better 1025 prepare marine managers for the future when more extreme ocean temperatures will be 1026 the 'new normal'.

Toc blurb

Prolonged ocean warming events, known as marine heatwaves, can have devastating impacts on ocean ecosystems and are becoming more frequent and severe. This Perspective explores the predictability of marine heatwaves, taking into account the physical processes responsible for their formation, and examines potential monitoring and prediction approaches and systems for mitigating their detrimental effects.

\section{Related Links}

1044 Integrated Marine Observing System - http://imos.org.au/

1045 Marine heatwave website - www.marineheatwaves.org

1046 Marine heatwave tracker - www.marineheatwaves.org/tracker.html 


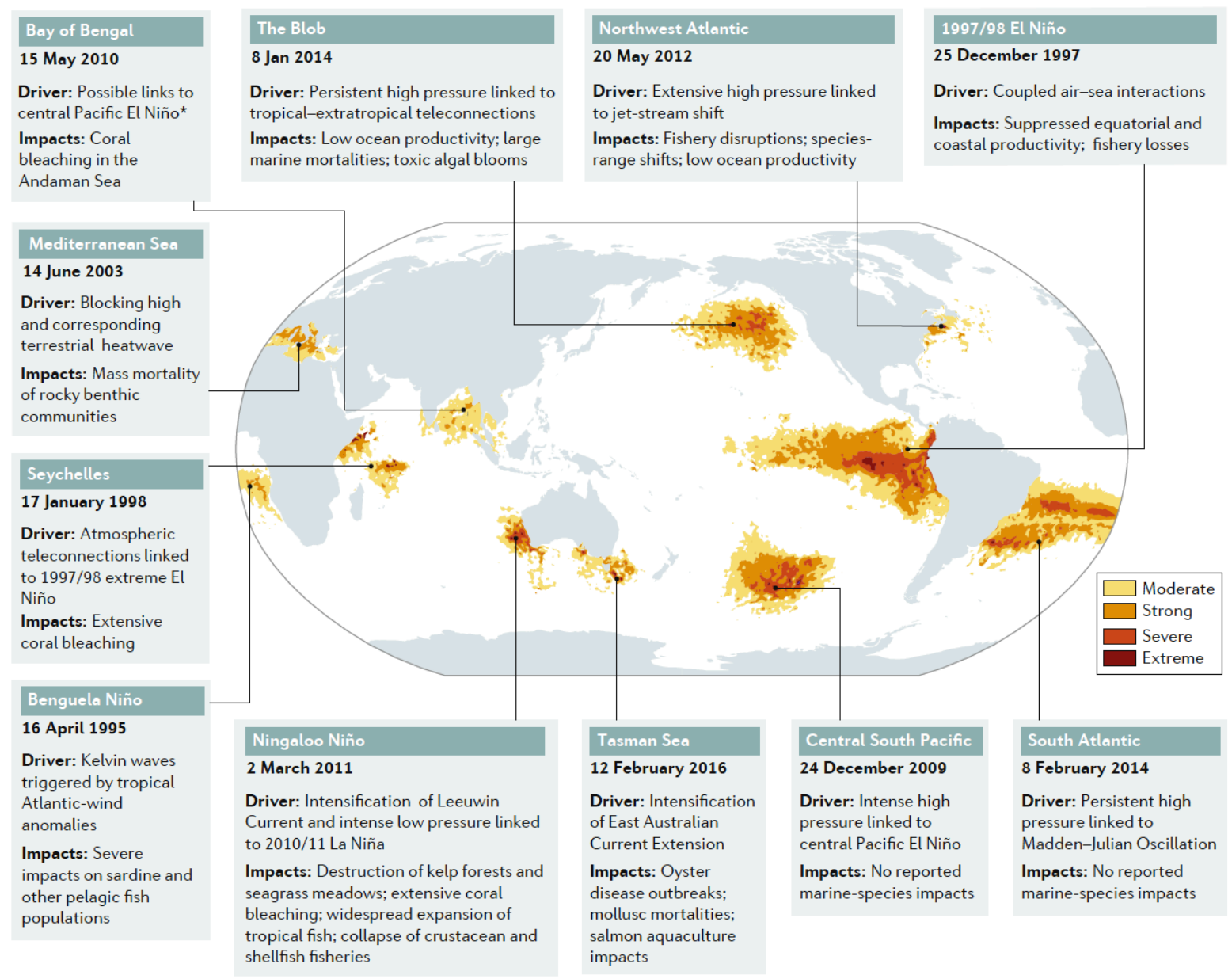

Figure 1 
a Globally averaged annual MHW days

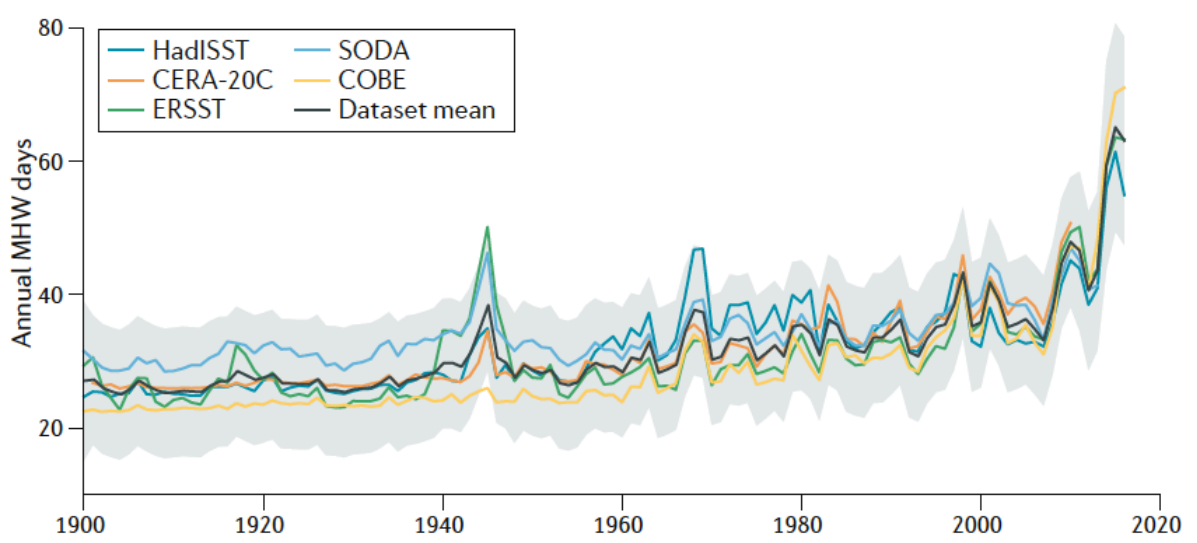

b Change in MHW days (1987-2016 minus 1925-1954)

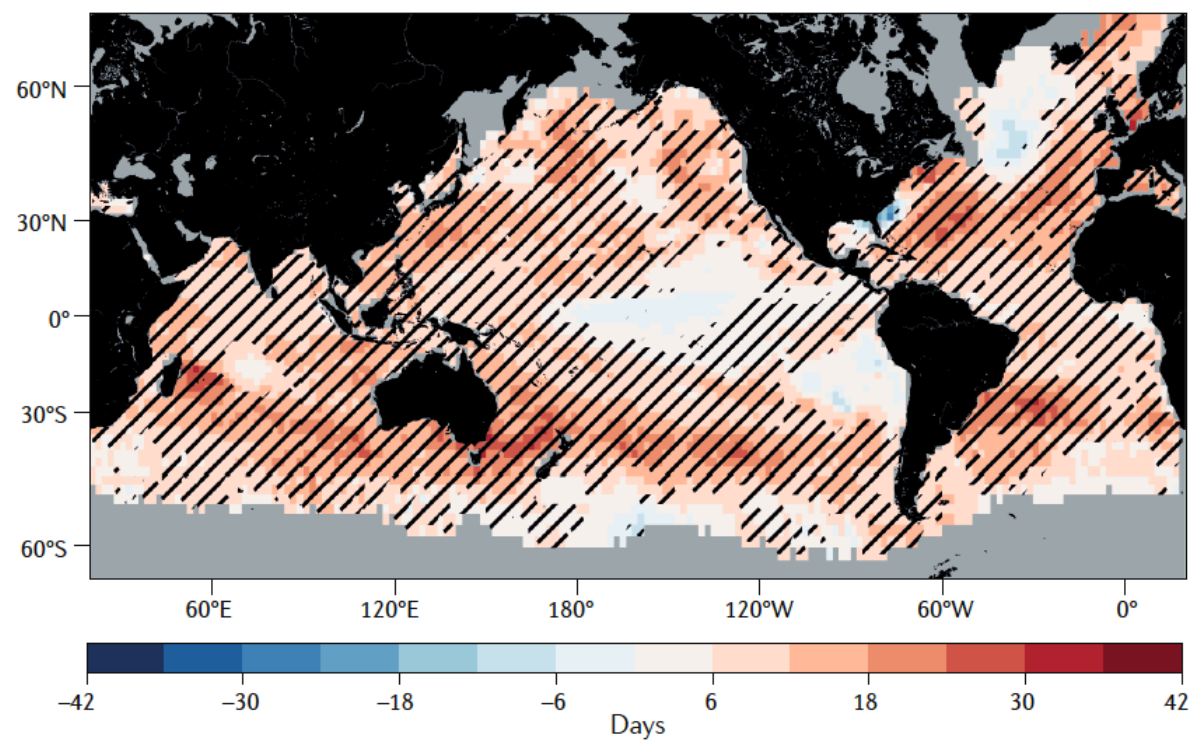

c Change in MHW days (2031-2060 minus 1961-1990)

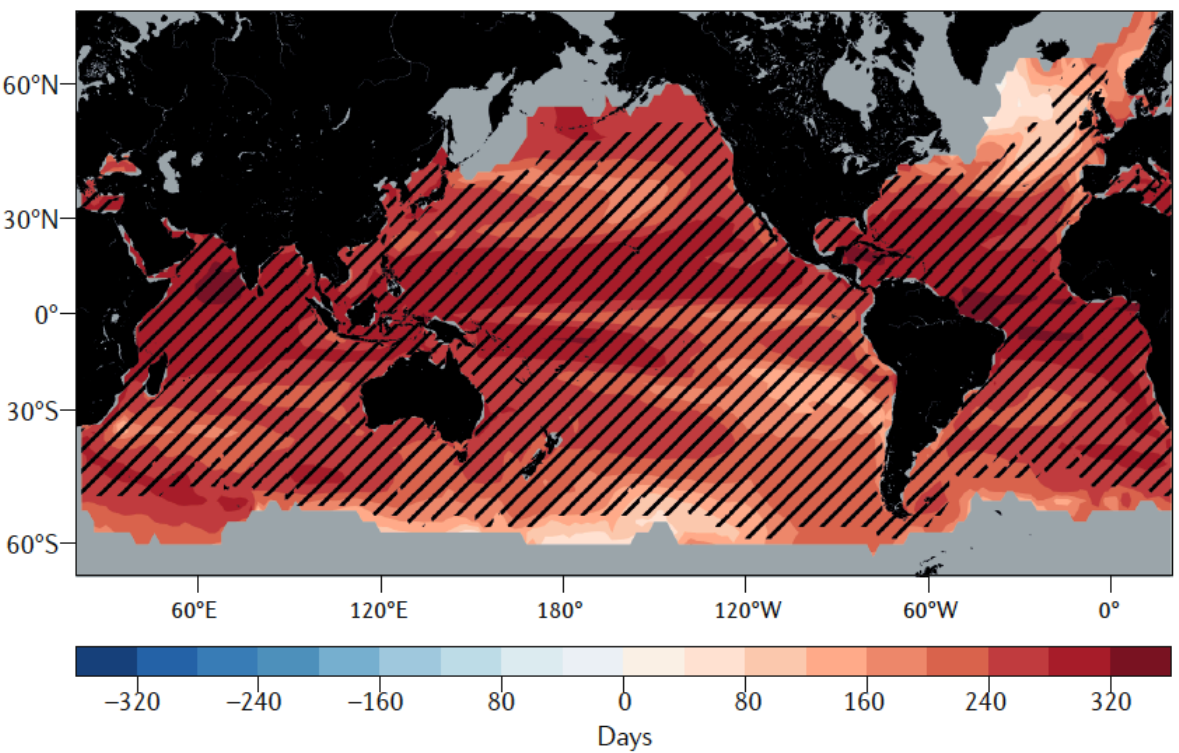

Figure 2 


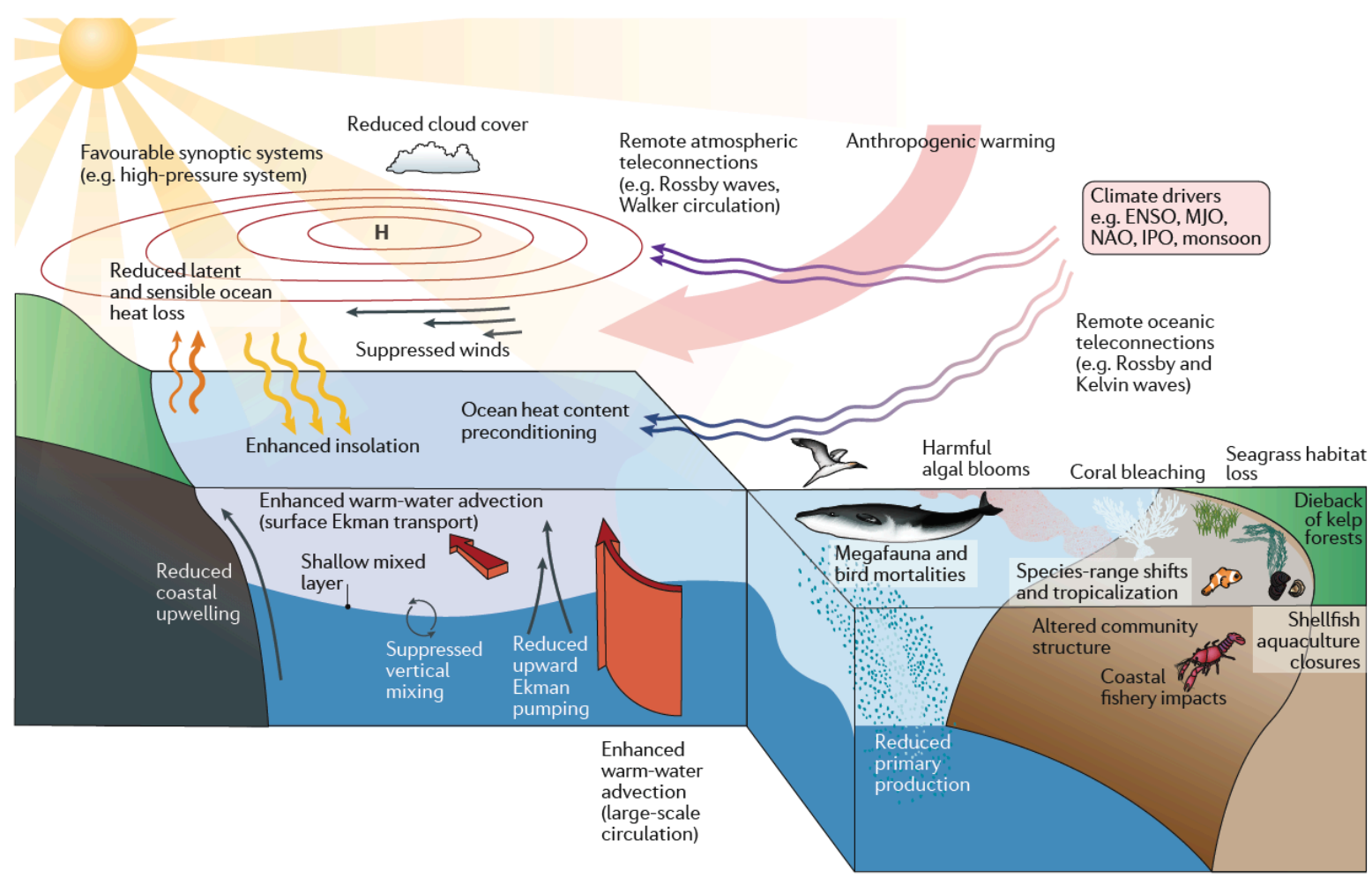

Figure 3 

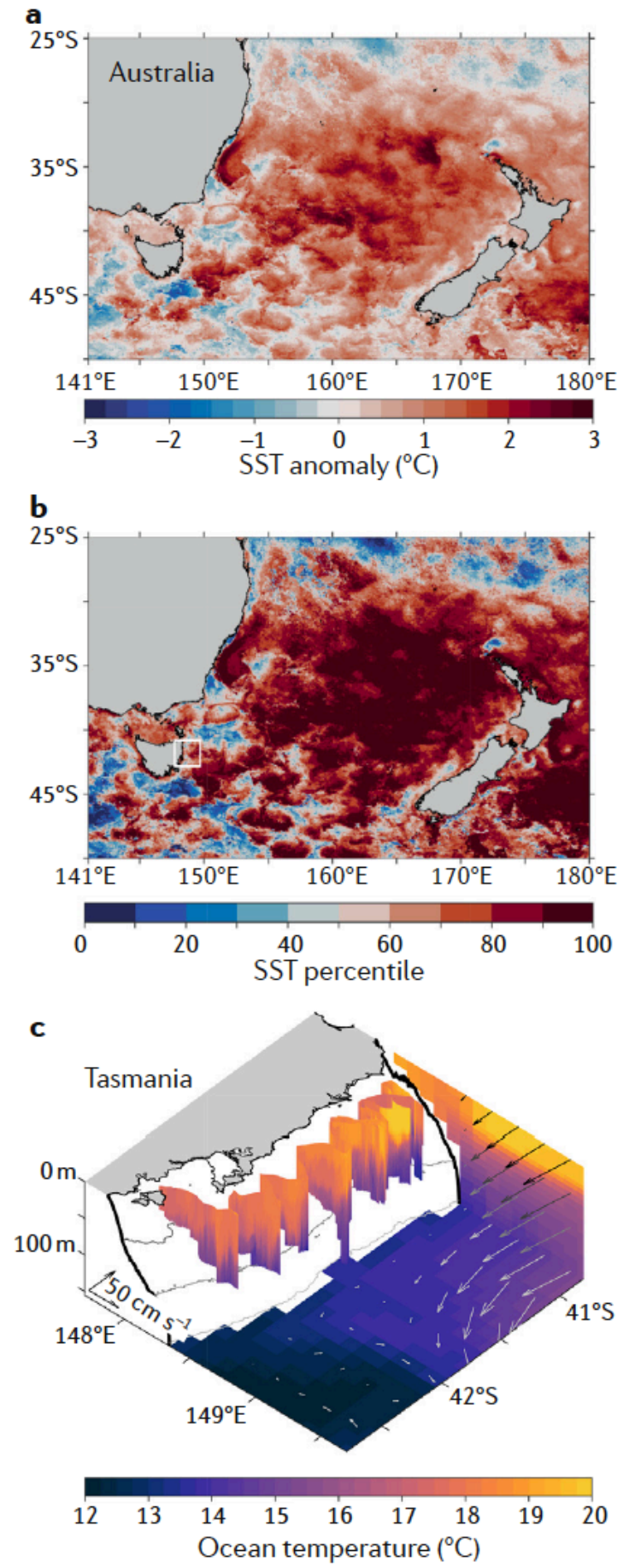

Figure 4 
Initial-value problem
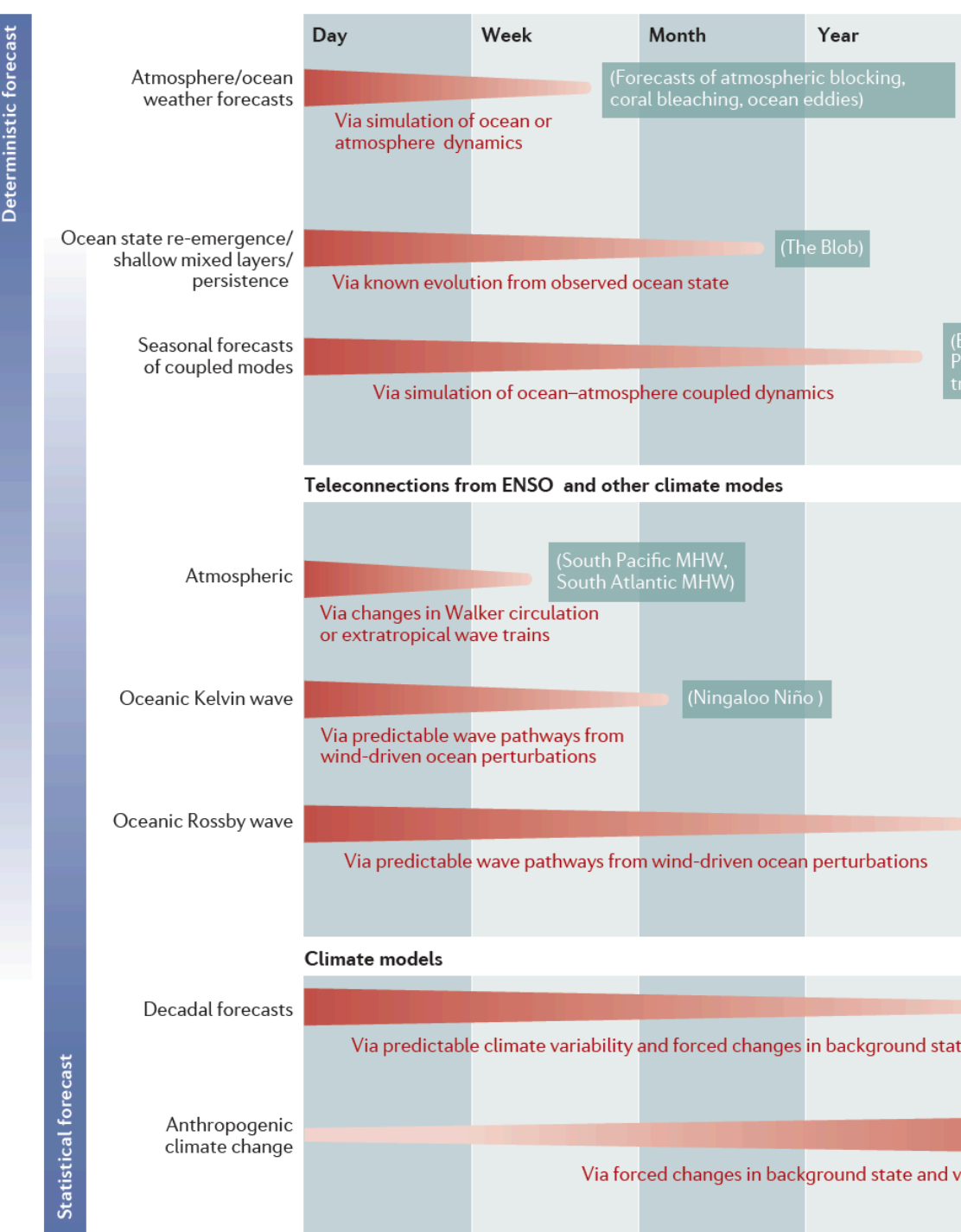

Decade

Century

Ocean state re-emergence/ shallow mixed layers/ persistence atmosphere dynamics

Seasonal forecasts of coupled modes
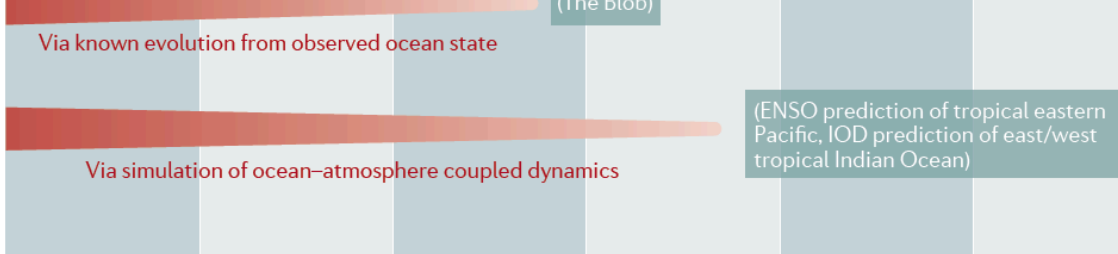
Pacific IOD prediction of east/west tropical Indian Ocean
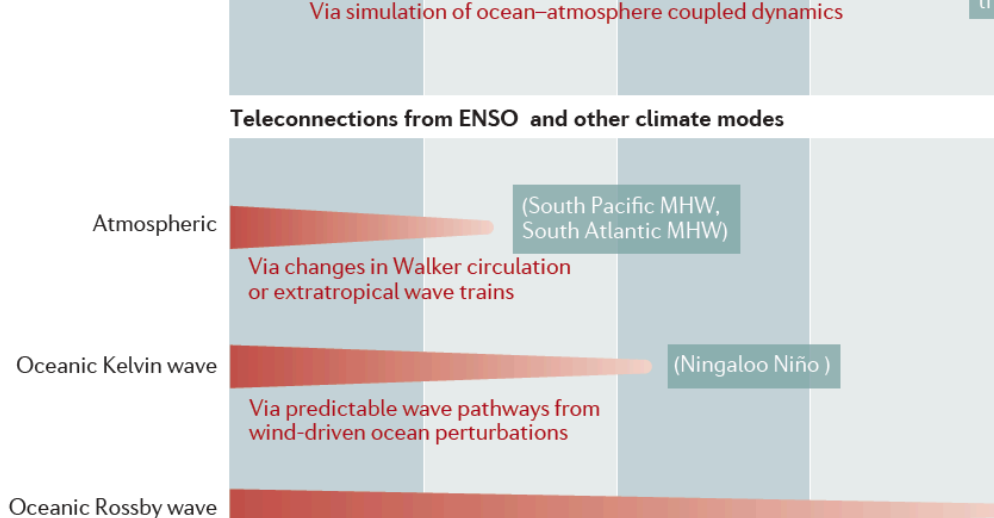

Oceanic Rossby wave
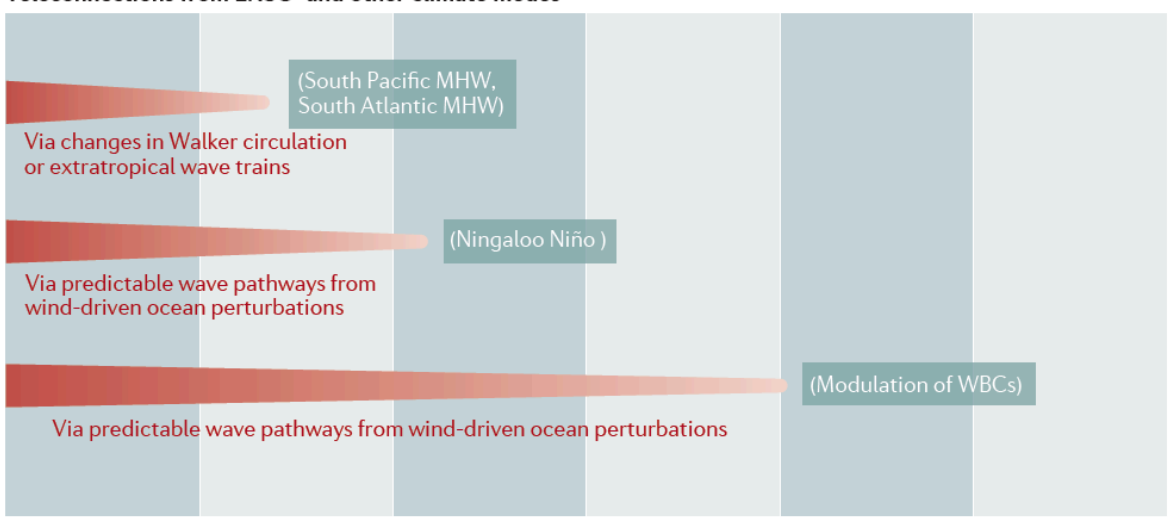

Climate models

Decadal forecasts

\section{Figure 5}

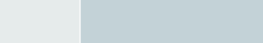



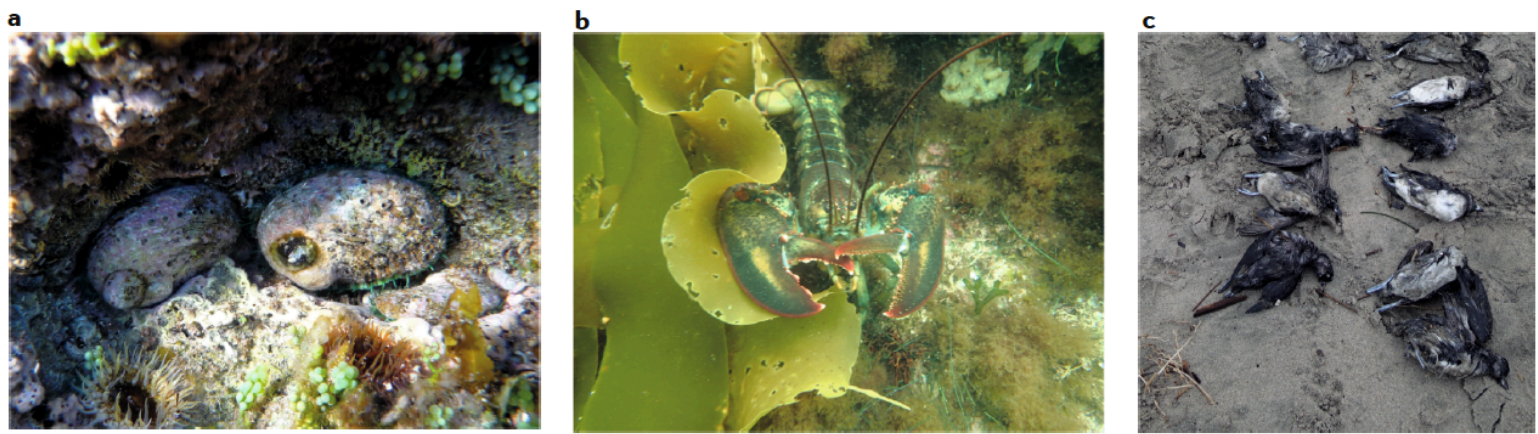

1068

1069

1070 Images Box 2 